\title{
Nudge, embarrassment, and restriction—replies to Voigt, Tieffenbach, and Saghai
}

\author{
Nir Eyal ${ }^{*}$ \\ *Correspondence to: Nir Eyal, Email: nir_eyal@hms.harvard.edu \\ Copyright: (c) 2015 by Kerman University of Medical Sciences \\ Citation: Eyal N. Nudge, embarrassment, and restriction-replies to Voigt, Tieffenbach, \\ and Saghai. Int J Health Policy Manag 2015; 4: 53-54. doi: 10.15171/ijhpm.2015.01 \\ Received: 27 November 2014, Accepted: 4 December 2014, ePublished: 5 December 2014
}

$I^{\prime}$ $\mathrm{t}$ is a privilege that some of the most promising contributors to public health ethics took the time to think and comment on my op-ed. Kristin Voigt's (1), Emma Tieffenbach's (2), and Yashar Saghai's (3) ingenious comments have taught me a lot about nudging, embarrassment, and restriction. Let me address their main points one by one.

Kristin Voigt makes two points. One is that nudging by shaming can be either paternalistic or non-paternalistic and that, like any intervention, it is easier to justify when it is nonpaternalistic. Indeed, whereas nudges were originally conceived as "libertarian paternalistic" and used behavioral psychology to promote paternalistic goals only $(4,5)$, nudges $(6)$ and behavior psychology in general $(7,8)$ can promote non-paternalistic goals as well. What is less obvious is that a paternalistic intervention is always harder to justify than a similar non-paternalistic one. Sarah Conly writes, "If it is permissible, even obligatory, to stop me when I do something that seriously interferes with someone else's chances of achieving the life he wants, I think it is equally permissible, and perhaps obligatory, to save me from myself" (7). In fact, is not it easier to justify forcing a child to eat her broccoli for her own sake than for her sister's sake-say, when her young sister looks up to her example? And isn't forcing a Jehovah's Witness to accept blood transfusion against his religious edicts easier to justify when the goal is paternalistic, to save his life-than when the goal is to save the lives of his starving related dependents?

Voigt's other comment is that there are two quite different routes through which zoning laws can shame or stigmatize smokers into quitting: directly, by temporarily shunning them from a certain geographical zone, and indirectly, by denormalizing smoking and provoking many instances of grass root social disapproval of smoking and of smokers. She says correctly that I was focusing on the first route and warns that the second, more dangerous route is a real potential.

In Voigt's second route, the intention to induce shame and stigma will typically be more transparent. That may weaken its impact on shame and stigma: "an expression of contempt may induce shame if seen as spontaneous but cause anger if seen as intended to induce shame" (8). Even if denormalizing turns out to be efficacious, it would be responsible both for making smokers' social lives harder in one respect and for a lot of quitting and a lot of smoking-prevention. So long as any resulting social penalties for smokers remain by and large moderate, denormalizing smoking would usually remain justified on balance. In every society, some behaviors are considered abnormal. Saving scores of lives is almost always worth the social risks and harms from limited added stigma, lamentable as the latter may be otherwise. Emma Tieffenbach points out that shame can be subjectively painful (it can be "felt as dread") and lead to destructive reactions like extreme anger. She concludes that shaming is not nudging: the latter is supposed to be costless.

Our preference for averting specific embarrassments of the form in which I am interested is adaptive (9). Once frustrated, that preference quickly wanes in strength, such that over our lifetimes, the overall hedonic loss from its frustration-the subjective cost-remains small. As an illustration, consider a person who is lonely because she moved to a new city but is too embarrassed to strike conversation with strangers. If somehow she found herself in conversation, the experience could be positive. Strong aversion to initiating conversations will have preceded the event. But if the embarrassment she dreaded materializes, it would not translate into a lasting strong unpleasant sensation-dreaded as it may have been. Such a person's form of embarrassment sharply contrasts with the lasting, deep shame and humiliation that can haunt victims of torture decades after physical pain is past (10). I believe that the embarrassment from not being permitted to smoke on the premises is a form of embarrassment (not deep shame) that worries us and may make smokingavoidance significantly likelier but that when it materializes, it rarely feels lastingly dreadful. Sunstein recently emphasized that what scares us and we are willing to pay plenty to avoid is not necessarily a very bad prospect (11). My proposal is to focus on a form of embarrassment that, thanks to our adaptive preferences, is not a very bad prospect.

Moreover, consider again the person who dreads conversation with strangers. If she were interviewed on whether a third party is promoting his own good by choosing loneliness over starting a conversation, she may well judge that lasting loneliness is worse than fleeting embarrassment. If asked to list the components of the good life, she is likelier to include on the list having friends than to include avoiding small embarrassments like starting a conversation. In a reflective moment, she may recognize that the dreaded embarrassment in fact is about a trifle; the sort of realization that can drive cognitive-behavioral therapy. Her strong (ex ante) preference to avoid embarrassment lacks her own endorsement (12). I believe that the same could be said about the embarrassment of, e.g. returning for many refills of one's soda cup, the example to which Tieffenbach reacts. These embarrassments are far less morally concerning than the obesity epidemic that they may help combat.

It is true that sometimes, people systematically underestimate in advance the toll of stigma and shame on them. According to some reports (13), many Iranian kidney sellers experience far more stigma than anyone could have predicted. Dostoyevsky's Raskolnikov winds up feeling more shameful about his 
crime than he had expected. But circumstances that tend to issue only in embarrassment that is adaptive and lacks the person's own endorsement are potentially characterizeable. If we studied what exactly tends to prompt that determinate form of embarrassment, we may identify psychic costs that are objectively small and that would be estimated as such by the person in hindsight and upon reflection, but that, in the moment, have tremendous impact on her choice. It is those embarrassments that I propose to leverage as nudges.

Tieffenbach and Voigt are also right that shaming and stigmatizing for good purposes are hard to contain. Some people would take small embarrassment too seriously; others would stigmatize too much, or for the wrong things, or stigmatize the wrong people. But could not the same be said of any health promotion policy? Simply being offered advice drives some people crazy. Surely we should not refrain from any social policy to which some may overreact.

Tieffenbach adds that even mild embarrassment should count as a significant cost compared to what it helps prevent-a single instance of drinking a supersize soda, or a single smoking break. This important point goes beyond my own discussion and challenges the use of nudges against recurring individually-minor behavioral choices in general. Default changes to the choice architecture that impose hardly any cost in a single instance impose a high cumulative cost (e.g. scores of embarrassments, scores of default changes). This is a powerful challenge to the nudge framework.

Finally, Tieffenbach points out that, being coercive, bans (in circumscribed geographical zones) on smoking or on selling supersize sodas cannot be pure nudges. But inasmuch as the main effect of these bans springs directly from the shame they elicit (and not directly from the ban), it seems fair to call them primarily nudges. By analogy, for Sunstein and Thaler, motivating people to do something by paying them handsomely is not nudging them; but motivating them to do it through a token payment is a nudge (5). Presumably, the reason is that the main effect of token payment on choice springs not directly from the desire for money but from other things, such as response to the message (of endorsement, say) that the token payment is understood to convey (14).

Where does all that leave us on the use of shame for public health? It is rash to condemn every shaming in the service of good causes (15), but Voigt and Tieffenbach are right to remind us about the dangerous potential of shaming, even in the service of public health. If we are to use slight shaming for public health in the safest, most targeted way possible, the mechanics and triggers of embarrassment and stigma should be studied more carefully.

Yashar Saghai focuses on the final part of my commentary, where I argue that, precisely for being noncoercive, nudges occasionally cause deep shame. I have interpreted this to challenge the Principle of the Least Restrictive Alternative (herein PLRA), but Saghai thinks that I challenged only an implausible version of that principle. He points out that any interesting version of PLRA has an "other things being equal" clause. In his view, any distinctive tendency of an alternative to shame violates such a clause.

I agree with Saghai that any interesting PLRA comes with such a clause [in fact, watch 1:18' of (16)]. However, "other things being equal" refers to exogenous and/or independent factors, usually not to dependent ones. The shame that nudging causes (in certain types of situation) is a dependent variable. A proper "other things being equal" clause would not screen it out. Saghai's own suggestion is that even an interesting PLRA remains wrong because "the least restrictive alternative is not always the easiest or least costly to implement". But a difference in ease or in cost of implementation strikes me as a violation of "other things being equal". He adds that "running through all the predictable consequences of feasible alternatives is not an easy task", but I suspect that this could be resolved by distinguishing between objective and epistemic versions of PLRA. Such a distinction is unavoidable for many moral and legal principles and is not a special problem of PLRA.

Let me end by thanking again Voigt, Tieffenbach, and Saghai for highly ingenious and thoughtful comments.

\section{Ethical issues}

Not applicable.

\section{Competing interests}

Author declares that he has no competing interests.

Author's contribution

$\mathrm{NE}$ is the single author of the manuscript.

\section{References}

1. Voigt K. Nudging, shaming and stigmatising to improve population health: Comment on "Nudging by shaming, shaming by nudging". Int J Health Policy Manag 2014; 3: 351-3. doi: 10.15171/ijhpm.2014.114

2. Tieffenbach E. On the cost of shame: Comment on "Nudging by shaming, shaming by nudging". Int J Health Policy Manag 2014; 3: 409-11. doi: 10.15171/ijhpm.2014.125

3. Saghai Y. Radically questioning the principle of the least restrictive alternative: a reply to Nir Eyal': Comment on "Nudging by Shaming, Shaming by Nudging". Int J Health Policy Manag 2014; 3: 349-50. doi: 10.15171/ijhpm.2014.106

4. Sunstein $\mathrm{CR}$, Thaler RH. Liberal paternalism is not an oxymoron. Univ Chic Law Rev 2003; 70: 1159-202. doi: 10.2307/1600573

5. Sunstein CR, Thaler RH. Nudge: Improving Decisions About Health, Wealth, and Happiness. 1st edition. New Haven, СT: Yale University Press; 2008. doi: 10.2139/ssrn.1361071

6. Korobkin R. Libertarian Welfarism. Cal L Rev 2009; 97. doi: 10.2139/ssrn.1361071

7. Conly S. Against autonomy. New York: Cambridge University Press; 2012.

8. Elster J. Alchemies of the mind: rationality and the emotions. Cambridge, New York: Cambridge University Press; 1999.

9. Elster J. Sour Grapes: Studies in the Subversion of Rationality. Cambridge: Cambridge University Press; 1985.

10. Margalit A. The Decent Society. Cambridge, MA: Harvard University Press; 1996.

11. Sunstein C. Valuing Life: Humanizing the Regulatory State. Chicago: University of Chicago Press; 2014.

12. Dworkin R. Sovereign Virtue: the Theory and Practice of Equality. Cambridge, MA: Harvard University Press; 2000.

13. Nejatisafa AA, Mortaz-Hedjri $S$, Malakoutian T, Arbabi M, Hakemi MS, Haghighi AN, et al. Quality of life and life events of living unrelated kidney donors in Iran: a multicenter study. Transplantation 2008; 86: 937-40. doi: 10.1097/ tp.0b013e318186d945

14. Benhassine N, Devoto F, Duflo E, Dupas P, Pouliquen V. Turning a Shove into a Nudge? A "Labeled Cash Transfer" for Education. NBER Working Paper No. 19227; 2014.

15. Nussbaum MC. Hiding from Humanity: Disgust, Shame, and the Law. Princeton, NJ: Princeton University Press; 2004.

16. Petrie Flom Center. VIDEO: Panel 1: "The Ethics of Nudges in Health Care”. 2014 Annual Conference: Behavioral Economics, Law, and Health Policy. Cambridge, Ma. 2014 [cited 2014 Nov 26]. Available from: http://petrieflom.law.harvard.edu/events/ details/2014-annual-conference 